\title{
Utilização de asfalto-borracha na restauração da pavimentação da rodovia $\mathrm{RJ}-122$
}

\section{Rubber asphalt application in RJ-122 highway paving restoring}

\section{Clara Toledo Siqueira, Carolina Cristina Barbosa, Caio de Azevedo Geraldo, Richard B. N.}

\section{Vital*}

Como citar esse artigo. Siqueira, C.T; Barbosa, C.C; Geraldo, C.A; Vital, R.B.N. Ultilização de asfalto-borracha na restauração da pavimentação da rodovia RJ-122. Revista Teccen. 2021 Jan./Jun.; 14 (1): 28-32.

\begin{abstract}
Resumo
O transporte rodoviário tem um papel fundamental para a economia brasileira e, por isso, garantir a qualidade e durabilidade das estruturas civis é um grande desafio para a Engenharia. Devido à escassez de recursos públicos para o desenvolvimento da infraestrutura de transporte, torna-se evidente a necessidade do desenvolvimento de materiais resistentes às condições climáticas adversas e alterações nas condições operacionais. No tocante aos pavimentos, uma solução que vem apresentando bons resultados do ponto de vista ambiental e aumento da durabilidade é o asfalto ecológico, que emprega pneus inservíveis. Nesse sentido, este trabalho discute os principais aspectos relacionados ao emprego do asfalto ecológico na restauração da pavimentação da rodovia fluminense RJ-122.

Palavras-chave: : Asfalto-borracha, pneus inservíveis, pavimentação.
\end{abstract}

\section{Introdução}

Como Brasil é um país de dimensões continentais, a integração dos diferentes modais de transportes (aéreo, rodoviário, ferroviário, hidroviário, etc) é de suma importância para permitir a movimentação de mercadorias e pessoas. Stefano (2016) descreve os gargalos da infraestrutura de transporte no Brasil e seus impactos econômico/social.

$\mathrm{O}$ transporte rodoviário começou a ganhar grande relevância na infraestrutura de transportes brasileira a partir de meados do século XX, com a introdução de políticas públicas de incentivo e desenvolvimento do parque industrial (Gomes, 2006). A Figura 1 mostra o crescimento da produção de autoveículos no Brasil, no período de 1957 a 2019, divididos em automóveis, que são os mais representativos, seguidos por veículos comerciais leves, caminhões e ônibus.

O crescimento da frota brasileira traz consigo efeitos financeiros e sociais (Silva, 2017). Algumas dificuldades estão relacionadas à redução da mobilidade urbana, elevação de custos para a construção e conservação de rodovias, além da deposição de insumos provenientes dos autoveículos, que tem vida útil limitada e tornam-se inservíveis após esse tempo.

Segundo Leite \& Motta (2019), a malha rodoviária nacional é composta por 1,72 milhões de quilômetros, distribuídos sob as jurisdições federal, estadual e 


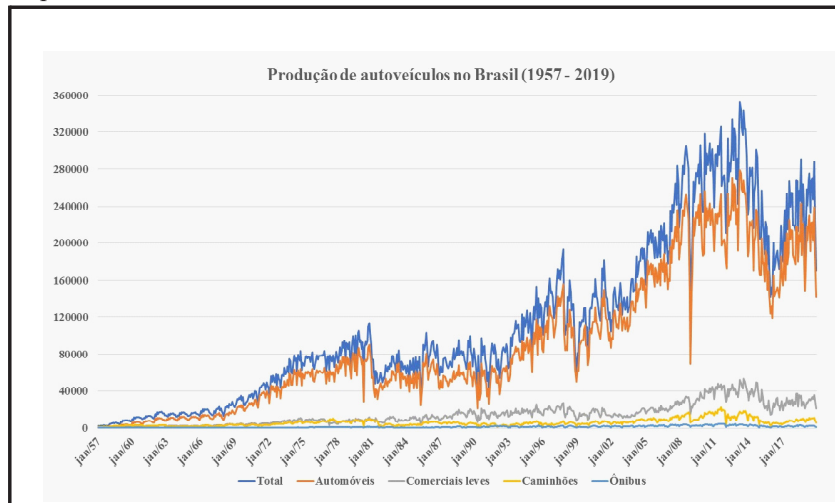

Figura 1. Evolução da produção de autoveículos no Brasil.

municipal. O Anuário da Confederação Nacional do Transporte de 2019 mostra que 120 mil quilômetros estão sob jurisdição federal, enquanto 1,6 milhões estão distribuídos entre os entes estaduais e municipais (CNT, 2019a). Segundo a Associação Brasileira de Concessionárias de Rodovias em 2018, mais de 20 mil quilômetros da malha nacional foram concedidos ao setor privado (ABCR, 2019). Uma análise das estatísticas disponíveis demonstra uma fragilidade da infraestrutura rodoviária brasileira, visto que apenas $12,4 \%$ das rodovias brasileiras são pavimentadas (CNT, 2019b).

Outro problema da malha está relacionado ao envelhecimento da pavimentação, que exige maiores investimentos em manutenção. $\mathrm{O}$ aparecimento de patologias pode ser decorrente de diversos fatores como: estimativa de tráfegos subestimada, falha de projeto, escolha inadequada de materiais, condições ambientais adversas, execução inadequada do leito, pavimento ou dispositivos de drenagem e, ainda, falta de manutenção periódica. Uma pesquisa desenvolvida pela CNT em 2019 em um universo de aproximadamente 109 mil quilômetros das estradas brasileira apontou que para o quesito pavimentação, apenas $47,6 \%$ foram classificadas como ótima e boa (CNT, 2019b). A escolha de materiais e técnicas construtivas de maior viabilidade econômico-financeira podem reduzir os custos com manutenção de veículos e da própria infraestrutura, além de proporcionar conforto e segurança aos usuários (Salviano, 2015; Norbak, 2018).

Fatores importantes relacionados ao transporte rodoviário são a composição e propriedades dos pneus para proporcionar segurança e, o conforto aos usuários nas rodovias (Rodrigues, 2008). Os dados da Associação Nacional de Indústria de Pneumáticos (ANIP) indicam que são vendidos anualmente quase 60 milhões de pneus novos no Brasil (ANIP, 2020). No universo analisado, verifica-se que as montadoras são responsáveis pela distribuição de aproximadamente $25 \%$ através de veículos novos e, a maior parcela, próxima de $75 \%$ são distribuídas como peça para reposição. A Figura 2 mostra a variação mensal de vendas de pneus no Brasil entre 2017 e 2019, obtidos dos infográficos mensais da ANIP. Neste gráfico pode-se observar vendas mensais superiores a 5 milhões de pneus.

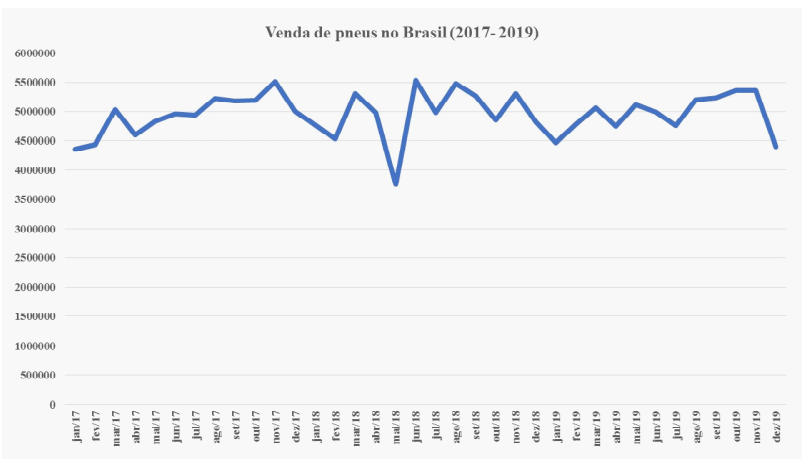

Figura 2. Evolução da venda de pneus novos no Brasil.

Para reduzir os danos ambientais provocados pelo descarte de pneus que ultrapassaram o seu período de vida útil, foi estabelecida no Brasil a Resolução ${ }^{\circ}$ 301/2002 pelo Conselho Nacional do Meio Ambiente (CONAMA) que definiu a reponsabilidade pelo descarte adequado dos pneus inservíveis (CONAMA, 2002; Motta, 2008). A legislação brasileira foi atualizada em 2009, através da Resolução $n^{\circ} 416 / 2009$, que exige dos fabricantes a destinação adequada de $100 \%$ dos pneus que entrar no mercado de reposição (CONAMA, 2009; Lagarinhos e Tenório, 2013). A Figura 3 ilustra a evolução da destinação de pneus no Brasil segundo a RECICLANIP, entidade criada por fabricantes de pneus novos no ano de 2007 (RECICLANIP, 2021). Neste gráfico pode-se observar o aumento significativo que ocorre a partir de 2009 com o estabelecimento da Resolução n 416/2009 do CONAMA.

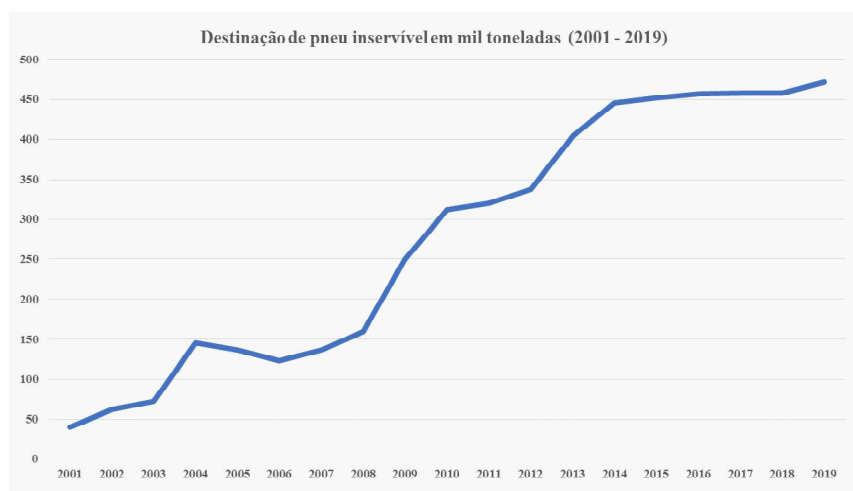

Figura 3. Evolução da destinação de pneus inservíveis no Brasil.

Apesar de não atender aos requisitos da área automotiva, o pneu inservível pode ser processado e utilizado em outras áreas como artefatos de borracha ou na construção civil (Yemal et al., 2011; Souza \& 
D’Agosto, 2013). Uma aplicação promissora consiste na utilização como ligante para os pavimentos flexíveis de rodovias sendo conhecido com asfalto-borracha ou asfalto-ecológico (Pinheiro, 2004). A aplicação dos pneus inservíveis na pavimentação foi normatizada no Brasil em 2009 pelo Departamento Nacional de Infraestrutura de Transportes (DNIT), através da norma 111/2009 (DNIT, 2009). A utilização do asfalto-borracha tem sido utilizada em vários países como: África do Sul (Renshaw et al., 2007), Brasil (Giulio, 2007; Balaguer, 2012; Zatarin et al., 2017), China (Zhu et al., 2014), Espanha (Gallego et al., 2000), Estados Unidos (Meneguini, 2011), Itália (Fornai et al., 2016), Portugal (Pereira, 2010), dentre outros. No Brasil diversas rodovias concedidas já empregam o asfalto-borracha em alguns trechos e novos projetos do setor público já vem considerando a aplicação desse material.

Em decorrência da necessidade de melhorar as estruturas rodoviárias brasileiras e garantir a preservação do meio ambiente, esse trabalho tem como objetivos: identificar as vantagens e desafios para a ampliação na utilização de pneus inservíveis; estudar as características do projeto de revitalização do pavimento da rodovia estadual RJ-122 que empregou uma técnica promissora na manipulação da matéria-prima.

\section{Material e Métodos}

Em função do desenvolvimento tecnológico e de novos materiais, os pneus começaram a ser inseridos nos veículos de transporte a partir de 1845 , substituindo madeira e ferro que antes eram empregados na produção de rodas (Rodrigues, 2008). Os pneus são construídos com diferentes matérias como: borracha (natural e sintética), aço e polímeros (poliéster ou nylon). Esses materiais são arranjados em uma dividida em: carcaça ou lona, que é a parte constituída por poliéster, nylon ou aço, para absorver os impactos e tensões do pavimento; talões, que são constituídos em aço, cuja finalidade é fixar o pneu à roda; flancos ou laterais, compostos por borracha flexível e resistente a fadigas; cintura, cuja função é suportar as cargas mecânicas provenientes do movimento de rotação; banda de rodagem, composta por borracha com finalidade de promover a aderência e estabilidade do veículo. O pneu é dimensionado de acordo com a condição climática na qual estará inserido, podendo ser dividido em pneu de verão, inverno ou para todas as estações.

Segundo a Resolução n 258/99 do CONAMA, os pneus podem ser divididos em três classes conforme descrito na Figura 4.

Devido aos materiais aplicados na produção, os pneus são produtos não biodegradáveis e este fato se tornou um grande problema ambiental, visto que descartados de forma inadequada na natureza, podem

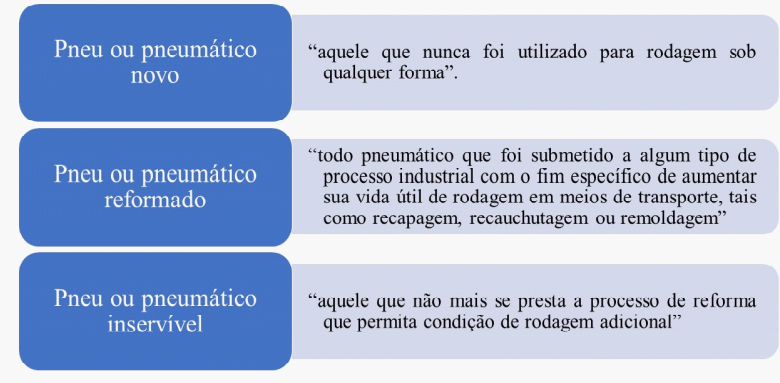

Figura 4. Classificação dos pneus segundo a Resolução 258/99 do CONAMA.

levar centenas de anos para a sua completa decomposição (Meneguini, 2011). Dessa forma, a reciclagem do pneu inservível é muito importante no tocante a preservação ambiental. Um método de reaproveitamento do pneu é a recauchutagem, que nada mais é que uma reforma no pneu, entretanto há um limite de recauchutagens. Existem outras aplicações do pneu na engenharia civil como barreiras em acostamento de estradas ou na composição do asfalto, também conhecido como asfalto-borracha.

Além dos aspectos ambientais, a introdução dos resíduos de borracha à pavimentação asfáltica convencional provoca a modificação de algumas das suas propriedades, levando a um aumento da vida útil e redução na frequência e custos com manutenção (Silva et al., 2018).

O asfalto-borracha apresenta uma redução da suscetibilidade térmica quando comparado aos pavimentos flexíveis convencionais, ou seja, as variações de temperatura operacional exercem menor influência sobre sua consistência, reduzindo a probabilidade de ocorrência de patologias. Adicionalmente, o pavimento torna-se maisflexível, visto que existem mais elastômeros na borracha de pneus e, dessa forma, agregados e ligante possuem maior adesividade e consistência, provocando um aumento da capacidade de impermeabilização. Devido à existência de maior concentração do elemento carbono e antioxidantes presentes nos pneus, o asfaltoborracha apresenta maior resistência ao envelhecimento que é diretamente proporcional ao tempo de vida útil do composto (Zatarin et al., 2017). Outra vantagem apresentada por Pereira (2010) é a redução de emissão sonora proveniente do contato dos pneus com o pavimento.

Zatarin et al. (2017) apresentam os resultados de um estudo que comprova a maior vida útil do asfaltoborracha comparado ao asfalto convencional. Esse estudo aponta como outra vantagem a necessidade de uma espessura menor do pavimento asfáltico com a adição de borracha de pneus.

O maior desafio para o aumento da aplicação do asfalto-borracha é o investimento inicial, que 
costuma ser bem maior que os pavimentos flexíveis convencionais (Mendes \& Nunes, 2009; Zatarin et al., 2017). Esse custo é associado a diversos fatores como a coleta de pneus e a existência de uma limitada cadeia de distribuição de materiais reciclados (Lagarinhos \& Tenório, 2013). Outro fator de impacto consiste na mistura, que dependendo do método de construção utilizado, pode demandar temperaturas mais elevadas para aquecimento da mistura. A questão dos recursos humanos também impacta no custo, visto que é limitada a mão de obra qualificada para esse tipo de solução.

O processo de fabricação do asfalto-borracha consiste na incorporação de borracha vulcanizada proveniente de pneus como modificador de ligantes asfálticos (Rosa el al., 2012). Esse processo pode ser dividido em dois grupos: no processo seco, a borracha triturada com uma determinada granulometria, com percentual entre 1 e 3\%, será incorporada como agregado fino em mistura betuminosa utilizando elevadas temperaturas através de um processo químico de redução; já no processo úmido, a borracha moída é adicionada ao ligante formando uma mistura sobre determinadas condições de temperatura que serão incorporadas posteriormente aos agregados (Balaguer, 2012). A Norma DNIT 111/2009 descreve os requisitos do processo úmido destacando o percentual mínimo de 15 $\%$ de borracha moída na massa do ligante, além de outras propriedades como: penetração, ponto de amolecimento, viscosidade, ponto de fulgor, estabilidade, variação em massa, entre outros (DNIT, 2009).

Existem dois processos que permitem a produção do asfalto-borracha: na Mistura Contínua em Usina (Continuous Blend), uma estrutura de pequeno porte que deve estar posicionada próxima ao canteiro de obras, controlando as propriedades da mistura através do aquecimento contínuo da mistura; na Mistura em Fábrica (Terminal Blend) o processo é executado em uma estrutura de grande porte que permite o controle mais adequado das propriedades da mistura, entretanto, a mistura possui um limite temporal para ser aplicada, o que aumenta o custo logístico e necessidade de planejamento de aplicação da mistura quando a usina está muito distante dos trechos que compõem o traçado da rodovia.

\section{Resultados e Discussão}

A aplicação do asfalto borracha na restauração da pavimentação da rodovia RJ-122, no ano de 2011, com o emprego de uma técnica de Mistura Contínua em Usina utiliza o conceito de água morna na composição dos agregados, mostrou vantagens e oportunidades que renderam ao projeto uma premiação internacional (DER-RJ, 2011).

A rodovia RJ-122, que está na jurisdição do estado do Rio de Janeiro, possui um traçado de 35,6 km cuja diretriz principal conecta os municípios fluminenses de Guapimirim e Cachoeiras de Macacu (SEAERJ, 2013). Além disso, essa rodovia interliga a rodovia federal BR116 à outra rodovia estadual, a RJ-116.

Segundo os requisitos apresentados em DNIT (2006), o projeto geométrico da rodovia é de Classe III e, o terreno da região pode ser considerado como ondulado (Akashi, 2011). A Tabela 1 mostra algumas características do projeto geométrico da rodovia RJ-122 que possui duas faixas de rolamento para cada sentido de deslocamento (DER-RJ, 2009).

De acordo com o DER-RJ (2011), a pavimentação da rodovia empregou 54 mil toneladas de resíduos de borracha provenientes de 200 mil pneus inservíveis a um custo total de $\mathrm{R} \$ 63$ milhões.

Tabela 1.Características da pavimentação da rodovia RJ-122.

\begin{tabular}{|l|c|}
\hline \multicolumn{1}{|c|}{ Característica } & RJ-122 \\
\hline Velocidade diretriz (Km/h) & 80 \\
\hline Largura da faixa de rolamento (m) & 4 \\
\hline Largura do acostamento externo (m) & 1,5 \\
\hline Vida útil (anos) & 20 \\
\hline
\end{tabular}

\section{Conclusão}

Como mostrado nesse trabalho, a aplicação do asfalto ecológico em rodovias brasileiras possui justificativas técnicas visto que melhoram as propriedades e consequente aumento da vida útil dos pavimentos, além do aspecto ambiental, uma vez em empregam materiais que possuem um longo período para decomposição e geram vários danos ambientais.

Dessa forma torna-se necessário um contínuo desenvolvimento de mecanismos de recolhimento e processamento dos pneus inseríveis, aliados a processos de aplicação mais eficientes e baratos.

Trabalhos futuros poderiam ser concentrar na comparação de valores e métodos utilizados para aplicação do asfalto ecológico nas rodovias sobre reponsabilidade estatal e aquelas concedidas à iniciativa privada.

\section{Referências Bibliográficas}

ABCR (2019). Relatório Anual 2018.

Akashi, S. H. M. (2011). Plano de controle ambiental: trecho da rodovia RJ122. Trabalho de Conclusão de Curso. Universidade Federal do Paraná. 
ANIP (2020). Infográfico ANIP - Dezembro de 2019.

Balaguer, M. (2012). Avaliação estrutural de um pavimento flexível executado em asfalto-borracha, elaborado pelo processo de produção contínua em usina. Dissertação de Mestrado. Rio de Janeiro: Instituto Militar de Engenharia.

CONAMA(1999). Resolução n ${ }^{\circ}$ 258/1999. Dispõe sobre a coleta e destinação final de pneus inservíveis.

CONAMA (2002). Resolução n 301/2002. Altera dispositivos da Resolução $\mathrm{n}^{\circ} 258$, de 26 de agosto de 1999, que dispõe sobre Pneumáticos.

CONAMA (2009). Resolução $n^{\circ}$ 416/2009. Dispõe sobre a prevenção à degradação ambiental causada por pneus inservíveis e sua destinação ambientalmente adequada, e dá outras providências.

CNT (2019a). Anuário CNT do transporte 2019.

CNT (2019b). Pesquisa CNT de rodovias 2019.

DER-RJ (2009). Projeto Básico de Recapeamento da RJ-122 entre Cachoeiras de Macacu e Guapimirim.

DER-RJ (2011). Governo do estado e DER-RJ inauguraram rodovia em Cachoeiras de Macacu. Disponível em: http:/www.der.rj.gov.br/detalhe noticia.asp?ident=270 Acesso em: 05 de setembro de 2020 .

DNIT (2006). Manual de estudos de tráfego. Rio de Janeiro.

DNIT (2009). Norma DNIT 111/2009 - Pavimentação flexível - Cimento asfáltico modificado por borracha de pneus inservíveis pelo processo via úmida, do tipo "Terminal Blending - Especificação de material".

Fornai, D., Sangiorgi, C., Mazzotta, F., Bermejo, J. M., Saiz, L. (2016). A new era for rubber asphalt concretes for the green public procurement in road construction. 1st European Road Infrastructure Congress, Leeds, United Kingdom.

Gallego, J., del Val, M. A. Tomás, R. (2000). A Spanish experience with asphalt pavements modified with tire rubber. Proceedings of the Asphalt Rubber 2000 Conference. Portugal, p.673-687.

Giulio, G. (2007). Vantagens ambientais e econômicas no uso de borracha em asfalto. Inovação Uniemp, v. 3, n.3.

Gomes, R. A. (2006). Transporte rodoviário de carga e desenvolvimento econômico no Brasil: uma análise descritiva. Dissertação de Mestrado. Brasília: Universidade de Brasília

Lagarinhos, C. A. F., Tenório, J. A. S. (2013). Logística reversa dos pneus usados no Brasil. Polímeros, v. 23, n. 1, p. 49-58.

Leite, L. F. M., Motta, L. M. G. (2019). Fator de ajuste de pagamento em obras rodoviárias: vantagens e desvantagens e utilização no Brasil. $9^{\circ}$ Congresso Rodoviário Português $\left(9^{\circ} \mathrm{CRP}\right)$, Lisboa, Portugal.

Mendes, C. B. A., Nunes, F. R. (2009). Asfalto borracha - minimizando os impactos ambientais gerados pelo descarte de pneus inservíveis no meio ambiente. Trabalho de Conclusão de Curso. Vitória: Faculdade Brasileira UNIVIX.

Meneguini, E. C. A. (2011). Avaliação de concreto asfáltico com incorporação de pó de borracha reciclada de pneus, tratada superficialmente com hidróxido de sódio comercial. Tese de Doutorado. Campinas: Universidade Estadual de Campinas.

Motta, F. G. (2008). A cadeia de destinação dos pneus inservíveis - o papel da regulação e do desenvolvimento tecnológico. Ambiente e Sociedade, v. 11, n. 1 , p. $167-184$.

Norback, C. (2018). Caracterização do módulo de resiliência e da deformação permanente de três solos e misturas solo-brita. Dissertação de Mestrado. Rio de janeiro: Universidade Federal do Rio de Janeiro.

Pereira, A. H. P. (2010). Caracterização acústica de pavimentos rodoviários e influência na emissão sonora. Dissertação de Mestrado. Porto: Universidade do Porto.

Pinheiro, J. H. M. (2004). Incorporação de borracha de pneu em misturas asfálticas de diferentes granulometrias (Processo úmido e Seco). Dissertação de Mestrado. Fortaleza: Universidade Federal do Ceará.
RECICLANIP (2021). Volume de pneus destinados. Disponível em: https:// www.reciclanip.org.br/destinados/ Acessado em: 05/05/2021.

Renshaw, R. H., Hoffmann, P., Potgieter, C. J. (2007). Bitumen rubber asphalt in South Africa and experience in China. Proceedings of the 26th Southern African Transport Conference (SATC 2007), Pretoria, South Africa.

Rodrigues, M. R. P. (2008). Caracterização e utilização de resíduos da borracha de pneus inservíveis em compósitos aplicáveis na construção civil. Tese de Doutorado. São Carlos: Universidade de São Paulo.

Rosa, A. P. G., Santos, R. A., Crispim, F. A., Riva, R. D. D. (2012). Análise comparativa entre asfalto modificado com borracha reciclada de pneus e asfalto modificado com polímeros. Teoria e Prática na Engenharia Civil, n. 20, p. 31-38.

Salviano, W. R. A. (2015). Análise do controle construtivo de um pavimento semirrígido por deflexão. Dissertação de Mestrado. Rio de janeiro: Universidade Federal do Rio de Janeiro.

SEAERJ (2013). Modelo Rodoviário - DER-RJ prevê investir R\$13, bilhão em estradas em 2014. Revista SEAERJ Hoje, n. 22.

Silva, W. N. (2017). Análise da mobilidade urbana por transporte sustentável nas cidades médias brasileiras. Tese de Doutorado. Rio de janeiro: Universidade Federal do Rio de Janeiro.

Silva, L. S., Nascimento, F. R., Nogueira, M. H. P., Lima, G. K. M., Sobrinho, D. C. R. (2018). Utilização de resíduos de borracha de recauchutagem de pneus na composição de asfalto. Revista de Ciência e Tecnologia, v.4, n. 7, p. 1-13.

Souza, C. D. R., D’Agosto, M. A. (2013). Análise dos custos logísticos aplicada à cadeia logística do pneu inservível. Transportes, v. 21, n. 2, p. $38-47$.

Stefano, E. (2016). Análise da evolução da pesquisa em Engenharia de Transportes. Tese de Doutorado. Rio de janeiro: Universidade Federal do Rio de Janeiro.

Yemal, J. A., Teixeira, N. O. V., Rodrigues, C. G. (2011). Fluxo reverso de pneus inservíveis na cidade de Santos. 3rd International Workshop Advances in Cleaner Production, Santos, Brasil.

Zatarin, A. P. M., Silva, A. L. F., Anemam, L. S., Barros, M. R., Chrisostomo, W. (2017). Viabilidade da pavimentação com asfalto-borracha. Revista Gestão \& Sustentabilidade Ambiental, v. 5, n. 2, p. 649-674.

Zhu, H., Cai, H., Yan, J., Lu, Y. (2014). Life cycle assessment on different types of asphalt rubber pavement in China. Proceedings of the International Symposium on Pavement LCA, Davis, California USA, p. 14-16. 